\title{
Os inventários da Celebração de Bom Jesus dos Passos, Oeiras, Piauí, Brasil
}

\author{
Áurea da Paz Pinheiro \\ Doutora; Universidade Federal do Piauí, Teresina, PI, Brasil; \\ aureapinheiro@ufpi.edu.br \\ Rita de Cássia Moura Carvalho \\ Doutora; Universidade Federal do Piauí, Cidade de Parnaíba, PI, Brasil; \\ cassia.moura@ufpi.edu.br \\ Francisco Stefano Ferreira dos Santos \\ Mestre; Universidade Federal do Piauí, Cidade de Parnaíba, PI, Brasil; \\ stefanof@ufpi.edu.br
}

\begin{abstract}
Resumo: O Nordeste do Brasil não é maciço e único, o Piauí, igualmente, é um território atravessado por singularidades, rico e complexo em patrimônios naturais e culturais, que ainda estão por serem investigados, registrados, comunicados e salvaguardados. Neste artigo, apresentamos notas de dois inventários do patrimônio cultural imaterial da Celebração de Bom Jesus dos Passos, um em 2007 e outro em 2019, no sertão do Estado. Dez anos separam esses inventários elaborados por uma equipe inter e multiprofissional, com a colaboração das comunidades locais detentoras dos patrimônios. Construímos olhares e percepções diversas de mundo, que nos permitiram coletar e registrar formas, cores, movimentos, dramatizações, teatralizações e diálogos mediados entre patrimônios, territórios e comunidades. Conseguimos narrar memórias e histórias da Celebração, que marcam o cotidiano, que aprofundam os laços de identidades das pessoas umas com as outras. Histórias presentes nas ruas, praças, casas, lugares de memória vivenciados e experenciados por devotos em rituais, festas e celebrações tradicionais da cultura brasileira, nordestina e piauiense em particular; histórias de homens, mulheres e crianças marcadas pela tradição cultural de um tempo presente, em rápida e constante transformação. Realizar inventários participativos é conviver com as pessoas, compreender que não existem histórias sem sentido, que é preciso encontrá-las onde quer que estejam.
\end{abstract}

Palavras-chave: Patrimônio Cultural Imaterial. Piauí. Inventários Participativos. 


\section{Introdução}

Ao longo desta narrativa, discorremos sobre conceitos, métodos, técnicas e desafios que nortearam a construção de Inventários do Patrimônio Cultural Imaterial no Piauí, Nordeste do Brasil. No percurso, seguimos as orientações da Constituição da República Federativa do Brasil (BRASIL, 1988), do Decreto Federal $\mathrm{n}^{\mathrm{o}} 3.551$, de 04 de agosto de 2000, que instituiu o Registro de Bens Culturais de Natureza Imaterial e criou o Programa Nacional do Patrimônio Imaterial (BRASIL, 2000) da Convenção para a Salvaguarda do Patrimônio Cultural Imaterial, aprovada em 2003 pela 32a sessão da Conferência Geral da Organização das Nações Unidas para a Educação, Ciência e Cultura (UNESCO, 2000).

Nos procedimentos teórico-metodológicos para construção dos Inventários, nos valemos das experiências e orientações de Pinheiro e Moura (2008), Varine (2013) e Cabral (2011), que são estudos básicos para produzirmos conhecimentos sobre os domínios da vida social aos quais são atribuídos sentidos e valores pelos detentores dos patrimônios. Portanto, são marcos e referências que nos orientam a refletir sobre identidades de grupos sociais e de comunidades que envolvemos ao longo dos trabalhos.

Em 2015, Arantes analisou a trajetória e os desafios do Inventário Nacional de Referências Culturais (INRC), considerado o principal instrumento usado pelo Instituto do Patrimônio Histórico e Artístico Nacional (Iphan) para a produção de conhecimentos e gestão do patrimônio cultural imaterial no Brasil. Informa-nos Arantes sobre as questões e decisões teórico-metodológicas, sobre os debates e as políticas públicas para essa natureza de patrimônio no País, o que inclui o Decreto 3.551/2000. Aponta a necessidade de revisões técnicometodológicas, após mais de 15 anos de aplicação do Manual de Aplicação do INRC, que orienta os processos de identificação, levantamento, descrição e sistematização de referências e bens culturais (FONSECA, 2005).

Morais e Ramassote, ao entrevistarem Arantes, nos informam sobre o relato do antropólogo: 
[...] a conversa aprofunda questões de cunho metodológico, no sentido de compreender as diferenças entre as técnicas e procedimentos de pesquisa utilizados pelo INRC e os empregados na pesquisa antropológica convencional, especialmente em relação às técnicas e métodos etnográficos; ela aborda, ainda, o papel do antropólogo nos inventários; comenta-se, por fim, a realização de inventários de bens culturais imateriais em outros contextos/países, em particular em Moçambique. Ao final, discutem-se mudanças nos modos de usar o INRC desde a sua criação, há 15 anos (a considerar o ano 2015), ao mesmo tempo em que se reflete sobre limitações, virtudes e possíveis revisões dessa metodologia. Foram inseridas, na edição desta entrevista, notas explicativas sobre pesquisadores e técnicos citados, além de outras informações contextuais, necessárias para a compreensão mais aprofundada dos assuntos abordados. (MORAIS; RAMASSOTE, 2015, p. 226)

Em 2020, vinte anos após a implantação do INRC (2000), com o uso do Manual de Aplicação, foi possível identificar e documentar o patrimônio cultural (no plural) nas cinco regiões do Brasil. Foram realizados mais de 150 inventários, que permitiram pesquisar, documentar, reconhecer, salvaguardar e comunicar a diversidade cultural brasileira; apreender sentidos e significados atribuídos por detentores e intérpretes das culturas locais, colaboradores fundamentais na conservação e salvaguarda dos patrimônios, agentes e setores públicos, privados e sociais.

No Piauí, ao longo desse período, a Superintendência do Iphan promoveu uma pesquisa para identificar os bens culturais representativos para a sociedade e comunidades locais. Com o uso do Manual de Aplicação foram realizados, inicialmente, os inventários da Arte Santeira, das Comunidades Quilombolas e da Cajuína.

Ao longo desses anos, nos inventários que realizamos, vivenciamos experiências singulares, sobretudo no que refere à aproximação com as comunidades detentoras dos patrimônios. Foram rodas de conversa e memórias, oficinas de fotografia e audiovisual, cursos de formação para educação para os patrimônios, que se constituíram em formas diversas de imersão nos territórios. Acreditamos que uma das maiores conquistas desses estudos e intervenções foi a criação em 2015, do Programa de Mestrado Profissional em Artes, Patrimônio e Museologia junto à Universidade Federal do Piauí, com a missão de formar gestores do patrimônio natural e cultural no Meio Norte do Brasil. Em 2020, já 
conseguimos formar mais de 40 gestores dos patrimônios, arte/educadores e museólogos, em um território rico e complexo em patrimônios, onde não havia esta natureza de formação.

Nos Inventários, associamos metodologias e técnicas colaborativoparticipativas, a exemplo a pesquisa-ação (THIOLLENT, 1985), etnografia (GEERTZ, 1989), história oral (ALBERT, 2013; THOMPSON, 1998). Adentramos os territórios (SANTOS, 1988), a vida cotidiana das comunidades (BAUMAN, 2003), o que nos permitiu realizar recolha de informações em formatos e suportes diversos.

A etnografia nos permitiu observar e interpretar ritos e festividades associados à religião, civilidade, ciclos do calendário etc., que ocorrem em ocasiões diferenciadas de sociabilidade, envolvendo manifestações culturais complexas, com códigos específicos, distribuição de papéis, preparação e consumo de comidas, bebidas, produção de vestuários, ornamentação de espaços e lugares, usos de objetos especiais, execução de músicas, orações, danças etc. Isso nos permitiu compreender sentidos e significados nos diversos territórios, que estudamos e intervimos.

Valemos-nos de uma descrição densa (GEERTZ, 1989) para registrar a riqueza de elementos remanescentes das raízes da colonização portuguesa no Piauí, com destaque para as celebrações com matrizes repletas de símbolos culturais, que justificam os registros, conhecimento, reconhecimento e proposição de políticas públicas estaduais e municipais para salvaguarda desses patrimônios.

Os inventários são importantes ferramentas nos processos de educação patrimonial, orientados pelo Iphan e comprovados nos trabalhos que realizamos, o que afirma modos eficientes de estabelecer relações com as comunidades locais em ações de mobilização e sensibilização para a importância do reconhecimento e valorização do patrimônio cultural. Ao longo desses mais de dez anos, promovermos atividades de formação e imersão nas comunidades, reflexões, diálogos entre conhecimento científico e empírico, buscando reduzir o caráter abissal que historicamente nos atravessa (SANTOS, 2007). Promovemos 
aproximações entre universidades, comunidades e agentes diversos nos territórios, o que nos permitiu fazer conexões de saberes, trocas de experiências. Nas pesquisas de campo, usamos técnicas básicas de levantamento documental, sistematização e interpretação de informações.

Inventariar é um modo de pesquisar, coletar e organizar informações sobre algo que se quer conhecer melhor. É necessário um olhar voltado aos espaços da vida, para identificar as referências culturais que formam o patrimônio cultural local. Com os inventários, documentamos um repertório de referências culturais, que constituem os patrimônios das comunidades, dos territórios, dos grupos que fazem da vida sociocultural, a partir de um olhar lançado por eles mesmos sobre seus patrimônios.

\section{0 território}

O lugar de imersão para construção dos Inventários de 2007 e 2019 é o sertão do Piauí, Nordeste do Brasil. Estudamos e intervimos pontualmente no município de Oeiras, primeira capital, que tem a sua história marcada pela colonização portuguesa desde meados do século XVII, e pelos movimentos de expansão da pecuária e de interiorização dos espaços coloniais da América Portuguesa.

Atraídos pela extensão das terras e abundância dos rios, condições propícias para a criação extensiva do gado, contingentes de desbravadores se espalharam pela área intermediária entre a bacia do rio São Francisco e a região do Maranhão. Tornaram-se donos de currais, expulsaram e dizimaram as populações indígenas, conquistaram as terras e constituíram as elites locais que se mantiveram secularmente à frente da organização política e social aristocrática e interiorana que marcou a história desses tempos e espaços (PINHEIRO; MOURA, 2008). A formação histórica do Piauí se caracteriza também pela forte presença dos missionários franciscanos e jesuítas, já que, como em todo o Brasil, a Igreja Católica acompanhava a conquista dos espaços coloniais portugueses pela evangelização e catequese dos índios e pelos serviços religiosos prestados aos colonos. 
No Piauí, a atuação da Igreja Católica nos séculos XVII e XVIII precedeu a constituição de vilas e cidades, pois, antes da instalação oficial da Capitania de São José do Piauí, os missionários já pregavam aos índios e faziam as desobrigas, percorrendo o sertão e administrando os sacramentos, assim que se constituíam as fazendas. A própria administração do Piauí Colonial, baseada na fundação de vilas, foi estruturada de acordo com as freguesias pré-existentes em diferentes e distantes lugares do território piauiense. Onde havia uma freguesia católica, passou a existir uma vila e, mais tarde, uma cidade. Os exploradores eram homens religiosos (PINHEIRO, 2001).

Essa marca da presença católica é responsável pelo substrato cultural profundamente religioso que permanecerá, com modificações e interferências, na formação cultural do Piaú, nas formas de religiosidade popular, na cultura devocional, como na reza do terço, nas novenas, nas procissões, nos festejos e nas celebrações aos padroeiros em cidades do interior.

No início do século XX, foi criada a Diocese do Piauí, que passou a organizar e direcionar o trabalho catequético feito junto às populações locais, tendo em vista que muitas das atividades religiosas populares eram, segundo a visão dos clérigos, feitas precariamente por irmandades religiosas leigas desde a segunda metade do século XIX. Entre elas, citam-se a do Senhor Bom Jesus dos Passos, da Nossa Senhora do Rosário e a do Glorioso São Benedito, constituídas oficialmente em 1859 na cidade de Oeiras como sociedades de sepultamento, organizações de ajuda mútua, centros da vida religiosa, além de serem responsáveis por organizar ritos, festas e celebrações em louvor aos santos devotos dos irmãos. Elas admitiam em seu quadro qualquer pessoa, independente de sexo, condição e estado, desde que professasse a religião católica.

A capital do Piauí, Oeiras, localizada no centro do território, em pleno sertão, em 1852 foi transferida para a recém-inaugurada Teresina, junto à foz do rio Parnaíba, planejada com a finalidade de abrir a economia e a sociedade piauienses às comunicações e aos contatos comerciais com o restante do império brasileiro. Apesar de concorrer com o comércio da cidade de Caxias, no 
Maranhão e ser ponto de contato mais próximo com a Europa e com o litoral, a nova capital não superou o caráter interiorano da sociedade piauiense, o que perdurou por muitas décadas e até bem recentemente, persistindo mesclado às sociabilidades e hábitos urbanos vindos de fora.

Quando os jesuítas iniciaram o processo de catequese das populações que habitavam a região, rituais tradicionais católicos passaram a se mesclar à devoção popular de culto às imagens, novenas, procissões e pagamento de promessas, com a produção de ex-votos, capelas e altares domésticos.

As contribuição cultural de escravizados vindos de África e dos nativos do território se materializa, sobretudo, na construção dos templos e em sua decoração, numa infinidade de oratórios domésticos, símbolos da fé de uma colônia obcecada pela ideia de pecado.

No imaginário produzido pelos artistas populares está presente ainda o ex-voto, que designa uma variedade de objetos doados por fiéis aos santos de sua proteção como forma de agradecimento por um pedido atendido. A cultura de trocas simbólicas (BOURDIEU, 2007), entre o santo e o devoto é uma manifestação artístico-religiosa que se liga diretamente à arte religiosa e popular desde os primórdios da colonização portuguesa no Brasil. As motivações do presente votivo são muitas.

No Piauí, as preces mais recorrentes são as de cura de doenças, pedidos por mais chuvas e por melhores colheitas, solicitações que se materializam em rituais de peregrinações às capelas e aos santuários, procissões, celebrações e louvores aos santos de devoção.

Com o processo de colonização portuguesa no Brasil e no Nordeste brasileiro, as práticas de trocas simbólicas se popularizaram. O santuário de Santa Cruz dos Milagres no Piauí é um desses lugares de peregrinação que recebe grande variedade de ex-votos trazidos pelos romeiros que para lá se dirigem para pagar promessas.

Desde o século XVIII no Piauí, formas de convívio, sociabilidade e vivências revelam a existência de práticas religiosas de cultos domésticos com o uso de altares particulares produzidos em madeira. Os equipamentos da moradia 
colonial, móveis e apetrechos produzidos em madeira informam sobre a existência de práticas de produção de oratórios, etc.

O caráter religioso e devocional foi plantado pelos primeiros missionários jesuítas, que trouxeram a arte erudita e a apresentaram aos nativos, que, usando a inventividade cabocla, se apropriaram de seu conteúdo para criar manifestações artísticas e práticas devocionais diversas (PINHEIRO, 2001).

A devoção popular, manifestada e ritualizada no culto a imagens de anjos e santos, nas procissões e nas promessas, foi e ainda é marcante na religiosidade e espiritualidade da sociedade piauiense desde a colonização. Romarias ao Santuário de Santa Cruz dos Milagres, no Piauí, e às cidades de Canindé e Juazeiro no Ceará são parte do calendário litúrgico, devocional e turístico de grande contingente da população piauiense, sobretudo do meio rural, e deixaram marcas profundas nas práticas religiosas e nos ambientes urbanos.

Exemplos recorrentes do que estamos afirmando se materializa nas origens da Arte Santeira do Piauí (PINHEIRO; MOURA, 2009), que pode estar ligada à arte popular de talhar, esculpir anjos, santos e confeccionar ex-votos, também chamados de milagres, artefatos feitos sob encomenda dos fiéis com fins religiosos. Muitos artesãos santeiros piauienses começaram produzindo cabeças, pés, mãos e demais partes do corpo humano para o pagamento de promessas, levados pelos devotos a templos e a santuários. Essa cultura, inclusive, era uma espécie de oferta religiosa não apenas para o fiel, que encomendava o ex-voto e o depositava na igreja, santuário ou sala de milagres como gratidão por um pedido recebido, mas para aquele que fabricava a peça e não cobrava o pagamento.

Hoje, muitos artesãos ainda se dedicam à arte dos ex-votos, sendo grande a procura de fiéis que frequentam igrejas e lugares de peregrinação e ali depositam o objeto-símbolo de sua promessa.

\section{Os Inventários}

$\mathrm{Na}$ construção dos Inventários privilegiamos o levantamento preliminar, a identificação e a documentação do ofício e os modos de fazer dos santeiros 
naquelas localidades. $\mathrm{O}$ conhecimento e documentação produzidos subsidiam o IPHAN/Piauí nas ações de salvaguarda da Arte Santeira, além de fornecer elementos para o processo de registro do bem no Livro de Registro dos Saberes, como estabelece o Decreto n. 3.551, de 04 de agosto de 2000 (BRASIL, 2000).

O trabalho inicial da equipe se caracterizou pelo estudo e familiaridade com os métodos e técnicas, construção dos referenciais teóricos em torno de memória, cultura, identidade, arte, bens e patrimônio cultural, pela pesquisa bibliográfica, e, ainda, pelos contatos preliminares com os santeiros nas localidades objeto do inventário.

As metodologias e técnicas da História Oral (ALBERT, 2013) e Etnografia (EVANS-PRITCHARD, 1950) foram usadas para complementar os instrumentos de pesquisa presentes no Manual de Aplicação e realizar os registros dos trabalhos de campo. Priorizamos as entrevistas temáticas com os devotos destacando a Celebração. A inserção dessas diferentes vozes, ainda que transcritas, segundo as orientações do Manual de Aplicação, pretendeu ampliar uma abordagem do discurso científico em direção a interpretações outras, advindas dos próprios participantes e devotos (SANTOS, 2007). Entrevistamos devotos de diversas faixas etárias e gerações, um universo multifacetado de pessoas com as quais falamos, com expressões devocionais recorrentes de um diálogo entre as diversas culturas que forjaram e têm reelaborado temporalmente a identidade brasileira e a nordestina em particular.

O estudo de fontes secundárias, as entrevistas temáticas e a convivência com os informantes permitiram ler a Celebração como um artefato representativo da cultura local-regional e, por conseguinte, brasileira. As entrevistas, mesmo privilegiando questões-problemas, possibilitaram conhecer as trajetórias de vida dos devotos, que têm suas existências assinaladas por uma religiosidade típica do Nordeste brasileiro, com vivências e experiências rurais e urbanas marcadas por uma espiritualidade peculiar.

A Celebração do Bom Jesus dos Passos ocorre no sertão do Piauí desde o início do século XIX, na cidade de Oeiras, antiga capital da Província. Reconhecida no município como patrimônio cultural imaterial, a Celebração 
tem rituais imersos na liturgia da Semana Santa, que iniciam na quinta-feira da semana anterior a ela, com a Procissão da Fugida, saída em procissão da imagem do Bom Jesus dos Passos da Igreja Matriz de Nossa Senhora da Vitória em direção à Igreja de Nossa Senhora do Rosário, onde permanece por toda a noite até às dezesseis horas do dia seguinte, quando tem início uma via sacra, em estilo português. A imagem segue em grande cortejo, acompanhada por mais de trinta mil pessoas em oração, algumas delas vestidas de roxo ou a carregarem ex-votos, e percorre as ruas estreitas da antiga e bem preservada cidade colonial, patrimônio nacional reconhecido pelo Iphan.

A cidade de Oeiras possui um rico e complexo patrimônio cultural, que expressa a cultura política, histórica e religiosa de seus habitantes. A marca da colonização portuguesa está no casario colonial dos séculos XVII, XVIII e XIX, nas festas e celebrações religiosas que atravessam a vida social até os dias atuais, no calendário litúrgico católico que dita a agenda sociocultural dos residentes. Por conta de seu rico e complexo patrimônio cultural edificado, no dia 27 de novembro de 2013, foi aprovado tombamento definitivo do Conjunto Histórico e Paisagístico de Oeiras, conforme Processo n. 1.602-T-10 (Processo n. 01450.006978/2010-20) pelo IPHAN (2013).

Os referidos bens culturais foram inscritos no Livro do Tombo Histórico, Volume III, fls. 81/86, sob o n. 622; e, no Livro do Tombo Arqueológico, Etnográfico e Paisagístico, Volume II, fls. 93/98, sob o n. 169. Amparo legal: Decreto-Lei n. 25, de 30 de novembro de 1937; Portaria n. 11, de 11 de setembro de 1986; Lei n. 9.784, de 29 de janeiro de 1999 e Decreto n. 6.844, de 07 de maio de 2009.

No entanto, existe um patrimônio cultural imaterial, que necessita ser inventariado, registrado, documentado, comunicado e salvaguardado, o que nos motivou a realizar um Inventário da Celebração, esta reconhecida pela população local como parte de suas memórias e histórias de vida, de seu patrimônio. Portanto foi da comunidade religiosa de Oeiras que partiu a demanda pelo inventário para sua salvaguarda.

A primeira capital do Piauí, Oeiras, é uma cidade marcada por símbolos

Em Questão, Porto Alegre, v. 26, p. 235-260, Edição Especial Dossiê Patrimônio e Culturas Tradicionais, 2020 | 244 doi: http://dx.doi.org/10.19132/1808-5245260.235-260 
do catolicismo, com valores culturais ligados à presença da Igreja Católica. As igrejas seculares da cidade fazem parte da paisagem urbana, sendo símbolos de fé e religiosidade. Entre elas, citamos a imagem de Nossa Senhora da Vitória, localizada no Morro do Leme e da Cruz de Pedra, fincada no mirante da urbe.

O cenário colonial, com seu significativo conjunto arquitetônico eclesiástico, remete ao século XVIII. A Catedral de Nossa Senhora da Vitória, construída em 1733, guarda valiosas relíquias em arte barroca, com imagens de anjos e santos e altar de tábua de retalhos, que são zelados com devoção pelas famílias oeirenses. O escritor José Expedito Rêgo, no hino aos 259 anos da Catedral de Oeiras, diz na estrofe inicial que: "Foi aqui ao redor de Teu vulto que a cidade surgiu e cresceu" (RÊGO, 2006). A Igreja Matriz é o coração da cidade.

O território que hoje abriga a cidade foi desbravado no século XVII pelo vaqueiro e colonizador Domingos Afonso Sertão, que instalou à margem do riacho Mocha a fazenda Cabrobó, que deu origem ao primeiro povoado do Piauí. Mas seu marco de formação religiosa se deu com a instalação da Freguesia de Nossa Senhora da Vitória do Brejo da Mocha em 1697.

Os padres jesuítas Miguel de Carvalho e Thomé de Carvalho, vindos de Pernambuco, tinham o propósito de marcar as novas terras com o sinal de Cristo, pelas mãos da Virgem, representada pela imagem trazida pelos sacerdotes. A capela foi erguida no mesmo local onde hoje está a Matriz de Oeiras. Era simples, feita de taipa e coberta de palhas, caracterizando o tipo de construção vernacular, em que se usam materiais e recursos do próprio ambiente da edificação, feita com técnicas passadas de geração a geração, que marcou o início da colonização católica no Piauí.

Nenhuma cidade é portuguesamente brasileira se não nasce ao derredor de uma igreja. E Oeiras não é diferente. Cresceu sob o vulto da velha matriz, criando forma de materializar a fé e a crença sertaneja através do povo, organizando ciclos de festas religiosas, mesclando o calendário da cidade com a devoção aos santos e santas (CARVALHO JR., 2010).

Da organização da Celebração participam o clero da Paróquia de Nossa 
Senhora da Vitória, o bispo da Diocese de Oeiras, membros de Associações Religiosas, como o Apostolado da Oração Sagrado Coração de Jesus, fundado na Paróquia de Nossa Senhora da Vitória em 22 de janeiro de 1899, antes mesmo da criação da Diocese de Oeiras, em 1949. Participam como cuidadores das imagens, famílias responsáveis pelos dos paços, floristas, devotos, de historiadores locais, professores e alunos da rede pública de ensino, além de representantes de instituições locais de salvaguarda, como o Instituto Histórico de Oeiras, fundado no dia 6 de janeiro de 1972.

A Semana Santa é uma das emblemáticas celebrações religiosas de Oeiras. As ruas estreitas e becos históricos ficam repletos de romeiros, pagadores de promessas a cantar e louvar. Representa para os católicos o coração do ano litúrgico, quando se celebram a paixão, morte e ressurreição de Jesus Cristo.

Antes de iniciar a Semana Santa, os católicos se preparam para o período da Quaresma, quarenta dias da Quarta-feira de Cinzas, quando os fiéis são marcados na testa com uma borra torrada de palha de carnaúba, sinalizando a condição de pecadores que precisam se redimir diante de Jesus e de seu Pai, e seguem até a quinta-feira da última ceia, quando Jesus lavou os pés dos doze apóstolos e fez com eles a ceia final, antes de ser crucificado.

Durante a Quaresma acontecem as vias sacras, repetidas nas quartas e quintas-feiras na Igreja Catedral de Nossa Senhora da Vitória, um ritual de condenação, crucificação e ressurreição de Jesus Cristo. Os fiéis lotam a Matriz vestidos de roxo, a cor da penitência, do sofrimento e do luto pela morte do filho de Deus. Durante esse período de quarenta dias, eles fazem promessas e acreditam que vestindo roxo estão mais próximos de Bom Jesus dos Passos.

Segundo o historiador Dagoberto de Carvalho Jr (2010), a devoção acontece há aproximadamente 300 anos. Contudo, um fato curioso reafirmou a origem remota da Celebração. Na planta da cidade, datada de 1809, já aparecem pequenas edificações conhecidas como "passos", em número de cinco, representando cada uma das estações da via sacra. São pequeninas capelas dispostas ao Conjunto Histórico e Paisagístico de Oeiras, lugares por onde passa a Procissão, o cortejo com orações e bênçãos. Eles têm a parte da frente voltada 
para o poente, demostrando o morrer e o nascer do Sol, num ato que simboliza a ressureição de Jesus Cristo.

A Semana Santa em Oeiras começa na Quinta-feira que antecede a Quinta-feira da Paixão, numa Celebração em honra ao Bom Jesus dos Passos. Segundo a professora Espírito Santo Rêgo, no livro Oeiras Tradição e Fé (2006), a partir das quinze horas do mesmo dia, sempre de meia em meia hora, os sinos da Catedral dobram em tom solene, específico e preparado para a Quinta e Sexta de Passos.

Os sinos parecem chorar, trazendo para a cidade uma atmosfera de tristeza e piedade, perceptível na fisionomia dos fiéis ao verem representada a dor vivida por Bom Jesus dos Passos. Os sons dos sinos seculares fazem um chamamento para as pessoas de longe e de perto chegarem diante da velha Igreja. Aos pés do Santo, rogam a Deus uma prece. O badalar dos sinos traz muitos fiéis vindos da zona rural em verdadeiras romarias, de outras cidades, do interior do Estado, da Capital, de outros Estados. O cenário urbano se transforma.

Às dezenove horas, a Igreja Matriz (Catedral), é tomada pelos romeiros, que assistem atentos à missa da Quinta-feira da Fugida, termo que simboliza a fuga de Jesus Cristo para o Monte das Oliveiras, onde, segundo a tradição bíblica, precisava rezar e preparar o espírito para a via dolorosa e para os momentos de flagelo.

A missa chega ao final. Diante da imagem do Senhor Bom Jesus dos Passos, em andor datado de 1856, acontece a cerimônia do canto do Miserere, versão musicada à capela do Salmo 50, feita pelo compositor italiano Gregório Allegri. Trata-se da palavra com que começa a Bíblia na sua tradução latina, a Vulgata. É o salmo mais conhecido de arrependimento pelo pecado e faz parte dos salmos penitenciais.

Vozes entoam estrofes lamuriosas e tocantes, que chegam a arrancar lágrimas dos devotos. Mantendo a tradição, a imagem é coberta por um dossel roxo para que não a vejam, representando a fuga, o esconder-se dos centuriões romanos. Após a cerimônia, a imagem sai em procissão, carregada por homens, 
em direção à Igreja de Nossa Senhora do Rosário, que fica em uma área elevada da cidade, numa espécie de colina, o Bairro do Rosário, habitado por remanescentes de populações escravizadas quando da colonização portuguesa no Piauí. A Igreja representa, na tradição oeirense, o Monte das Oliveiras. No templo católico, a imagem é venerada durante toda a noite.

A Procissão da Fugida segue até o Bairro em silêncio, rompido apenas pelos sinos da Catedral e da Igreja do Rosário. Até a década de 1960, apenas os homens acompanhavam a Procissão. Hoje, homens e mulheres acompanham a Procissão de Fugida, que dura aproximadamente uma hora. Quando chegam à Igreja do Rosário dos Pretos, o dossel, uma espécie de cortina portátil, quadrilongo de tecido decorado com franjas, sustentado por hastes, é retirado e a imagem é descoberta. Novamente é cantado o Miserere e os sacerdotes incensam a imagem de Bom Jesus dos Passos, como sinônimo de divindade. É feita a aspersão da água benta e a benção sacerdotal. Sobre a cabeça do Bom Jesus está o resplendor de prata, fazendo jus à sua condição de rei.

O Horto do Bairro Rosário, ornado com alecrim, planta nativa da região, da espécie Rosmarinus officinalis e com flores artesanais de passo, feitas de forma artesanal, com papel de seda laminado, colados com cera de abelha e com suporte em talos de buriti ou coco, se transforma no Santuário do Senhor Bom Jesus. O alecrim, cujo torna o ritual místico, é a essência perfumada do Santo devoto de Oeiras, o odor da redenção dos devotos.

A túnica roxa do Santo é constantemente tocada pelos fiéis, que nela depositam esmolas, além de pedidos de cura do corpo e da alma. O olhar expressivo da imagem oitocentista emociona os romeiros, que não cansam de tocar a cruz, os cabelos e a coroa de espinhos sobre a cabeça de Bom Jesus.

Durante a noite da Quinta para a Sexta-Feira dos Passos, as famílias católicas de Oeiras ornam as capelas dos Passos com André-Miúdo, planta nativa da região, que, juntamente com o alecrim, perfumam o ambiente sagrado, e com as flores de passos, como são conhecidas em Oeiras.

A origem do uso das flores é desconhecida, segundo Francisco Rêgo, um dos devotos, responsáveis por preparar a imagem de Bom Jesus. Sabemos 
apenas que existem em Oeiras e fazem parte da alegoria da Celebração, oferecem alegria e beleza às estações da via-crucis. Segundo o autor, os Passos têm sua frente voltada para o poente, demostrando o morrer e o nascer do Sol, numa metáfora da ressurreição.

Quando o sol nasce na sexta-feira, dia do Bom Jesus dos Passos, a igrejinha do Rosário repica o sino das seis horas, despertando a cidade. As ruas, ornadas com flâmulas roxas, acenam para os romeiros que chegam em caravanas para assistirem à primeira missa do dia na Catedral. Ao meio dia da sexta-feira é rezado o Ofício dos Passos na Igreja do Rosário. Centenas de fiéis participam. O ofício é melodiado por vozes que ora rezam, ora cantam o martírio de Jesus Cristo, e relatam a paixão e morte de Bom Jesus. A assembleia de participantes faz um ato de contrição, pedindo perdão a Deus pelo sofrimento de redentor. Esse é para os romeiros um momento de agradecer e de fazer pedidos ao Santo.

O Ofício dos Passos é constituído de rezas e cantos dos quais o padre não participa, pois são os devotos que o celebram. A religiosidade ocorre de forma concentrada, com forte conteúdo messiânico e nordestino. Possui mais de 400 versos, divididos em dez partes, decassílabos e redondilhas, cantados ou declamados sob forma de oração. Sua composição guarda semelhanças com os versos dos romances das feiras do Nordeste do Brasil.

A partir das dezesseis horas, o Largo da Igreja do Rosário é tomado por uma multidão de mais de trinta mil romeiros. É o grande público da Procissão que vê, no sofrimento de Cristo, o seu próprio sofrimento. Olhando do alto da torre da velha Igreja, é possível perceber a imensa cortina roxa que toma conta das ruas de Oeiras. São pagadores de promessas, com pedras na cabeça, de pés descalços, carregando cruzes, com flores de Passos na mão e muita fé.

No interior da Igreja há uma enorme movimentação. Os sacerdotes cuidam dos paramentos. Os homens que carregam o andor com a imagem do Bom Jesus vestem a roupa roxa, uma espécie de camisola para se diferenciarem dos demais fiéis, representando a irmandade, que receberam dos antepassados e cuja tradição eles mantém e levam adiante. Eles carregam nas mãos hastes de 
ferro conhecidas como descansos, que servem para sustentar o andor quando a imagem para diante dos Passos.

Os sinos da Igreja de Nossa Senhora do Rosário repicam outra vez, chamando os romeiros para o interior da Igreja. Os sacerdotes, acompanhados dos ajudantes de cerimônia, se posicionam em frente à imagem, que se encontra na capela-mor. Cantam novamente o Miserere (Salmo 50) da misericórdia; a imagem é incensada ao som das vozes que cantam: "Tende piedade, Senhor, e sê clemente tua bondade, apague os meus pecados".

A bênção da imagem é feita pelo bispo diocesano, que segura nas mãos a relíquia da Santa Cruz, um fragmento que se acredita ser da cruz original em que Jesus Cristo foi crucificado. É um símbolo da fé católica. A relíquia foi trazida para Oeiras pelo terceiro bispo da Diocese, Dom Edilberto Dinkelborg, que geriu a Diocese de 1959-1991, cujos restos mortais estão depositados na Capela do Bom Jesus, na Igreja Nossa Senhora da Vitória de Oeiras. Após a benção, a imagem sai da Igreja, carregada por homens que herdaram dos antepassados a tarefa de carregadores do Bom Jesus.

A imagem do Santo é vestida com uma túnica roxa, cabelos longos e humanos, sobreposta em um andor de madeira, atado com duas cordas e sobre a sua cabeça é colocada uma coroa de espinhos para designar a condição de rei. A sua fronte está perfurada. As mãos, maltratadas, seguram uma cruz como sinal dos pecados da humanidade e detém sobre sua cabeça uma auréola de prata, mostrando a divindade do Santo (RÊGO, 2006).

Acompanham a imagem quatro lanternas de prata do século XVIII. À frente, estandartes ou flâmulas romanas roxas demonstram o poder do Império Romano. Uma das flâmulas traz a seguinte inscrição em latim: S.P.Q.R, Senatus Populusque Romanus, ou seja, o senado e o povo romano. Os católicos de Oeiras, em sua fé, modificaram de forma cristã o sentido da inscrição para Salvai Povo Que Remi, e pedem a salvação a Jesus, pelo perdão dos pecados através das indulgências.

A imagem é retirada do interior da Igreja e colocada no adro do Rosário. Atrás, os sacerdotes e o bispo que acompanham debaixo do pálio dossel, uma 
espécie de toldo coberto com varas de prata, guardando a pessoa do bispo como sagrada.

Antes dos estandartes romanos e logo depois da imagem do Bom Jesus, quatro personagens bíblicos participam do ritual. São mulheres, jovens vestidas com trajes típicos da época de Jesus, que representam as santas mulheres que seguiram Cristo até o calvário: Verônica, Maria Madalena, Maria de Cléofas e Salomé. Verônica carrega nas mãos um fragmento de tecido, como se fosse um pergaminho, com uma pintura que representa a face do Bom Jesus. É o Sudário, desenrolado por ela em todas as estações ou passos.

A Procissão segue após a Verônica abrir o sudário e cantar a lamentação do Profeta Jeremias, em latim: Ó vos ommes, qui transitis per viam, atendite et videte si est dolor sicut dolor, dolor meus, meus, meur; traduzida para o português: Caminheiros que passais por este caminho parai e olhai por favor se neste mundo existe uma dor assim tão grande, como uma dor de minha dor, de minha dor. Verônica é conhecida em Oeiras como Maria Beú, em razão da estrofe final do canto em latim meus. Com o passar dos séculos, as pessoas entendiam beú em vez de meus. E assim passaram a chamá-la de Maria Beú.

O canto é repetido nos cinco Passos, dispersos pelo Centro Histórico de Oeiras. Ora é cantado em latim, ora em português, sempre de forma intercalada. O cortejo sai em procissão acompanhado pela Banda de Música Santa Cecília, criada em 1940, sempre presente nos eventos festivos da cidade, e que, ao longo do trajeto, executa o Dobrado de Bom Jesus dos Passos.

Cada passo (capela) apresenta duas estações da via-crucis. Como só existem cinco passos em Oeiras, o encontro em frente à Casa de Câmara e Cadeia e o final da procissão na Igreja da Vitória são considerados passos para totalizar catorze estações $(7 \times 2=14)$. Em cada passo repete-se o ritual. O coral canta, o sacerdote queima incenso, dá benção do Santo Lenho e Verônica canta de novo as palavras de Jeremias.

Os fiéis acompanham o cortejo com paradas nos Passos até a Praça das Vitórias, em frente ao antigo Palácio da Cidade, hoje Prefeitura de Oeiras ou Paço Municipal. Quando a Procissão chega ao Centro Histórico de Oeiras é 
quase noite. Os sacerdotes se dirigem às janelas do Sobrado, Prefeitura de Oeiras, e um deles faz o Sermão do Encontro entre Jesus Cristo e sua Mãe.

O andor de Nossa Senhora é levado por mulheres que fazem parte do Apostolado da Oração do Sagrado Coração de Jesus, irmandade religiosa secular a zelar pelas tradições religiosas da cidade. As duas imagens se encontram, a Procissão continua e para ainda em dois passos, sendo que um deles o Passo do Engano, quando a imagem dá três rodadas, simbolizando que Jesus desejava enganar os seus malfeitores. Reza a tradição oeirense que, no momento da cerimônia do engano, os fiéis devem fazer pedidos e orações.

Ao chegar à Catedral de Nossa Senhora da Vitória, a Procissão segue para o adro da Igreja. São entoados o Miserere e o canto de Maria Beú. As imagens do Bom Jesus e de Nossa Senhora adentram o templo, aclamadas por palmas e cantos piedosos. Muitos fiéis, que durante o cortejo pagaram suas promessas, se despedem dos Santos, colocando esmolas e pedindo que no ano seguinte estejam novamente acompanhando a Procissão.

As imagens permanecem expostas para a visitação até as vinte e duas horas, quando a Igreja é fechada. Com a Procissão do dia seguinte, são mais de quarenta e oito horas de intensas orações e manifestações de fé que fazem parte das comemorações em honra a Bom Jesus dos Passos de Oeiras.

\section{Os desafios}

Ao longo das pesquisas para os Inventários, o trabalho de campo nos colocou desafios de método e epistemológicos, sobretudo, no que tange à produção de conhecimento sobre o outro. Como estabelecer uma relação dialógica, participativa, colaborativa, que superasse as relações de poder historicamente construídas entre pesquisadores e detentores dos patrimônios?

Não tivemos a pretensão de sermos autoridades nas histórias e memórias que reconstruímos, que narramos. Mas apenas de sermos capazes de promover escutas, coletas e registros de experiências com o trabalho de campo para a produção dos inventários. Sabemos da necessidade de uma autorreflexão, e a fizemos, o que nos permitiu detectar continuidades, permanências, rupturas, memórias subterrâneas e muitas vezes em disputa (NORA, 1993; 
HALBWACHS, 1993), nos colocando desafios éticos. Temos consciência de que os registros são frutos de uma síntese, organização e interpretação de dados coletados, sistematizados, interpretados, que comunicamos e que não estamos isentos do lugar coletivo de nossas falas.

Sabemos que os Inventários que construímos não são capazes de repor a originalidade da realidade vista, vivida e sentida no trabalho de campo, levando em consideração um conjunto de variáveis que a pesquisa eventualmente não nos permitiu. E que a própria inscrição da cultura na temporalidade submete a mudanças, uma cultura híbrida, fluída, como são as identidades, como são os patrimônios.

Não tivemos como apreender a totalidade, a complexidade do real, daí porque a nossa descrição, mesmo que pretensamente densa, é parcial. Sabemos que as memórias capturadas são trabalhadas e permeadas de ressentimentos, conflitos e vivências construídas ao longo do tempo e de gerações. Nosso intento foi capturar os sentimentos de artistas, artesãos, devotos, registrar os sentidos que atribuem à arte e às celebrações no momento particular de suas histórias de vida, percebendo a sedimentação de experiências e as contribuições do passado, aceitando ou rejeitando a abertura às mudanças e aos desafios do tempo presente.

Acreditamos que registrar, documentar e comunicar o patrimônio cultural é contribuir para a salvaguarda de ofícios e modos de saber-fazer, formas de expressão, lugares, celebrações. É permitir a comunicação e o fortalecimento de identidades e proporcionar a melhoria das condições de vida cotidiana das comunidades. É proporcionar encontros, diálogos com as populações, que conhecem e reconheçam manifestações culturais de suas localidades como referências e elementos de sustentabilidade. Isso tudo justifica acreditarmos em investigações dessa natureza, que nos permitem acessar memórias e manifestações culturais significativas.

Em várias partes do mundo existem monumentos, sítios históricos e paisagens culturais, mas não só de bens culturais materiais se constitui a cultura. Há outras manifestações emblemáticas que exemplificam manifestações 
transmitidas oralmente, materializadas em rituais, celebrações, festas que são recriadas individual e coletivamente, modificadas ao longo do tempo, de geração em geração. No Piauí, há exemplos significativos de patrimônios culturais imateriais a serem investigados, registrados, conhecidos e salvaguardados como importantes no rol do patrimônio cultural brasileiro, não apenas para apreciar, mas para democratizar o acesso e sugerir políticas de salvaguarda.

Ao longo desses mais de dez anos, identificamos, registramos, sistematizamos e construímos fontes significativas sobre o patrimônio cultural imaterial do Piauí. Divulgamos esses inventários em publicações em suportes diversos, publicações que nos permitem ampliar ações de salvaguarda e de educação e interpretação patrimonial, o que inclui a comunidade ordinária dos territórios e comunidade escolar. São famílias, alunos, professores, muitos deles detentores dos patrimônios, que há tempos anseiam por conhecimentos e reconhecimento desses bens como elementos formadores do patrimônio cultural brasileiro.

O trabalho de campo nos colocou desafios de método e epistemológico, sobretudo no que tange à produção de conhecimento sobre o outro. Como estabelecer um diálogo entre os pesquisadores e os detentores do patrimônio, participantes da pesquisa, os produtores dos bens culturais que inventariamos? Como estabelecer uma comunicação entre informantes, interlocutores, mediadores e os processos de produção?

Não foi nossa pretensão ser autoridade nos Inventários, mas sermos capazes de promover uma autorreflexão e compreensão sobre o que vimos, ouvimos e sentimos na experiência com o trabalho de campo para a produção dos registros audiovisuais e textuais.

Sabemos que essa postura autorreflexiva nos permite, cotidianamente, continuarmos a realizar inventários, detectar continuidades, permanências, rupturas, memórias subterrâneas e muitas vezes em disputa o que nos impõe desafios éticos enquanto pesquisadores em diálogo com dos detentores dos patrimônios, participantes da construção dos Inventários, pois temos consciência 
de que os registros e interpretações são produtos e reflexos de sínteses, organização e interpretações de dados coletados e que não estaremos isentos do nosso lugar social de fala (FOUCAULT, 1990).

Estamos convictos de que os dados que nos permitiram produzir palavras, imagens, sons, não são capazes de repor a originalidade da realidade vista, vivida e sentida no trabalho de campo, ao levarmos em consideração o conjunto de variáveis que a pesquisa pode sistematicamente não dar conta. Isso inclui a própria inscrição da cultura na temporalidade, que a submete à mudança.

Não tivemos e não temos como apreender a totalidade e complexidade do real, daí porque a nossa descrição, mesmo que pretensamente densa (GEERTZ, 1989), será sempre parcial, lacunar, incompleta. Sabemos que as memórias capturadas, são trabalhadas, ressignificadas no presente, permeadas de ressentimentos, conflitos, experimentos e vivências construídas ao longo do tempo e de gerações (BOSI, 1987).

Como orienta a discussão norteadora dos Inventários, nosso intento tem sido captar referências culturais para e com as comunidades, num trabalho participativo, para, juntos, atribuirmos sentidos e significados em momentos particulares, sociais e históricos no qual estamos inseridos. Com isso, percebemos a sedimentação de experiências e contribuições do passado, mas aceitando a abertura das manifestações culturais às mudanças e desafios de um tempo presente fluido, em constante e rápida mutação.

Usamos nos inventários um conjunto de métodos e técnicas, dentre as quais destacamos a elaborada por Antonio Arantes, da Universidade Estadual de Campinas, São Paulo, por solicitação do Iphan, publicadas por aquele órgão de proteção do patrimônio, no Manual de Aplicação do Inventário Nacional de Referências Culturais. No que se refere aos Inventários, suas técnicas, Arantes nos orienta:

[...] nossa recomendação é que elas sejam constituídas por pessoas com conhecimento da temática do patrimônio nas seguintes áreas: ciências sociais (particularmente antropologia), história, arqueologia, letras, museologia, arquitetura e geografia, em número e proporção variáveis de acordo com cada situação considerada. Ao 
participarem do levantamento preliminar, esses profissionais estarão sendo capacitados para atuar posteriormente como supervisores do trabalho de campo, acompanhando, revendo e sistematizando os dados obtidos pelos demais pesquisadores ao longo de todo o processo de investigação. (ARANTES, 2001, p. 35)

Hugues de Varine (2013) aborda o tema dos inventários, nos apresenta uma série de recomendação, possibilidades de trabalho de registro e salvaguarda do patrimônio cultural. Para o autor, os inventários participativos possibilitam uma experiência patrimonial que valoriza a população detentora de heranças ancestrais. Eles permitem trocas entre saberes tradicionais e acadêmicos que colaboram com um sentimento de pertencimento das pessoas em relação àquilo que consideram patrimônio cultural.

\section{Considerações Finais}

Os processos de construção dos inventários podem ser considerados ações de educação patrimonial, por incluírem o patrimônio vivo, ressignificado ao longo de anos por grupos sociais em diversos territórios e contextos socioculturais.

[...] são ricas e complexas as relações entre patrimônio, educação e museus. Frente às crises políticas e econômicas, buscamos viver em um mundo atravessado por antagonismos os mais diversos, sobretudo, aqueles referentes às relações dos seres humanos com o ambiente, com o patrimônio cultural e natural, assim devemos considerar as interfaces entre cultura e economia, mas não perder de vista a importância da consciência social, sensível e cidadã. (PINHEIRO, 2015, p. 55)

Segundo Varine (2013), a principal dificuldade para a elaboração de um inventário é a escolha do método, visto que muitos são carregados de academicismos e desconsideram o desenvolvimento local. Para corroborar, cita Paulo Freire (2011), que denominava de inventários meramente bancários, puramente passivos, ao se referir à educação formal no Brasil. Ao criticar os vários tipos de inventários, Varine (2013) os classifica em tecnocráticos, científicos e compartilhados, porém destaca a pertinência do inventário participativo ou compartilhado com a solução viável para valorização da comunidade. 
O Decreto no 3.551, de 04 de agosto de 2000, institui o Registro de Bens Culturais de Natureza Imaterial que constituem patrimônio cultural brasileiro e criou o Programa Nacional do Patrimônio Imaterial:

Art. $1^{\circ}$ Fica instituído o Registro de Bens Culturais de Natureza Imaterial que constituem patrimônio cultural brasileiro.

$\S 1^{\circ}$ Esse registro se fará em um dos seguintes livros:

(...)

II - Livro de Registro das Celebrações, onde serão inscritos rituais e festas que marcam a vivência coletiva do trabalho, da religiosidade, do entretenimento e de outras práticas da vida social;

$\S 2^{\circ}$ A inscrição num dos livros de registro terá sempre como referência a continuidade histórica do bem e sua relevância nacional para a memória, a identidade e a formação da sociedade brasileira (BRASIL, 2000, grifo nosso)

Portanto,

Registrar o patrimônio cultural é contribuir para a preservação de saberes, experiências e práticas tradicionais, é permitir a divulgação e o fortalecimento de identidades culturais locais e proporcionar a melhoria das condições de vida cotidiana de uma dada comunidade (PINHEIRO, 2009, p.11).

A concepção do inventário participativo está atravessada pelo debate sobre o direito de decisão sobre o que se deve salvaguardar e, portanto, merece esforços do poder público para sua valorização, difusão e salvaguarda, o que evidentemente deve ser um direito e dever de todos (VARINE, 2013). O autor destaca a importância de uma ação participativa e colaborativa, somada aos esforços de toda a sociedade, de forma integral e integradora, que permitam escolhas de registros e abordagens do patrimônio. Chama a atenção para possíveis equívocos e enfatiza a necessidade de construir um método a partir de uma investigação-ação que contemple os anseios e inquietações das comunidades em relação aos seus patrimônios:

Fazer um inventário participativo não é, entretanto, um trabalho de etnologia, sobretudo se ele tem realmente por objetivo o desenvolvimento local, pois para o etnólogo, pouco importa que uma tradição esteja morta, contanto que seja conservada sobre um suporte durável e analisada cientificamente em nome do conhecimento. Para o agente de desenvolvimento, o patrimônio imaterial faz parte integrante da cultura viva da população: sua materialização, sob forma escrita ou audiovisual, é secundária. Não 
existe um especialista autorizado para tanto, mesmo que as técnicas sejam por vezes as mesmas que as do etnólogo (VARINE, 2013, p. $55)$.

Percebemos a importância da escolha de uma natureza de registro que valorize os diferentes agentes sociais na busca por um inventário compartilhado. Nos trabalhos que realizamos, escolhemos os inventários participativos, porque valorizam os patrimônios vivos e, sobretudo, as pessoas. Essa postura colabora, de modo efetivo, para reforçar os laços de pertencimento da população em relação às suas referências culturais. $\mathrm{O}$ autor nos lembra de que

Para a própria população, assim como para cada um de seus membros, o inventário do patrimônio não é necessário, ao menos enquanto este permaneça vivo e conserve uma significação para cada um e para todos. (VARINE, 2013, p. 46)

Salvaguardar o patrimônio cultural imaterial é propor políticas de conhecimento e reconhecimento, de sentimento de pertencimento das comunidades, o que significa que devemos entender patrimônio cultural como marcas de identidades de grupos humanos diversos e complexos, que vivem em territórios e compartilham memórias e histórias, um presente, um futuro, modos de vida, crises e esperanças.

\section{Referências}

ALBERTI, Verena. Manual de história oral. Rio de Janeiro: FGV, 2013.

ARANTES, Antônio Augusto. Patrimônio Imaterial e Referências Culturais. Tempo Brasileiro. Patrimônio Imaterial, Rio de Janeiro, Tempo Brasileiro, n. 147, out./dez. 2001.

BAUMAN, Zygmunt. Comunidade: a busca por segurança no mundo atual. Editora Zahar, Rio de Janeiro, 2003.

BOSI, Ecléa. Memória e Sociedade. Lembranças de Velhos. São Paulo: EDUSP, 1987. v. 1.

BOURDIEU, Pierre. A economia das trocas simbólicas. São Paulo, 2007.

BRASIL. Constituição da República Federativa do Brasil, 1988.

BRASIL. Decreto $\mathbf{n}^{\mathbf{0}}$ 3551, de agosto de 2000. Institui o Registro de Bens 
Culturais de Natureza Imaterial que constituem patrimônio cultural brasileiro, cria o Programa de Patrimônio Imaterial e dá outras providências.

CABRAL, Clara Bertrand. Património Cultural Imaterial: Convenção da Unesco e seus Contextos. Lisboa: Edições 70, 2011.

CARVAlHO JR., Dagoberto Ferreira de. Passeio a Oeiras. Dagoberto de Carvalho Jr. 6. ed. Teresina: Fundação Cultural do Piauí, 2010.

EVANS-PRITCHARD, E. E. Social anthropology and other essays. New York: The Free Press, 1962.

FONSECA, Maria Cecília Londres. O patrimônio em processo: trajetória da política federal de preservação no Brasil. 2. ed. Rio de Janeiro: Editora UFRJ/MinC - Iphan, 2005.

FOUCAULT, M. As palavras e as coisas. São Paulo, Martins Fontes, 1990.

FREIRE, Paulo. Pedagogia da Autonomia: saberes necessários à prática educativa. 43. ed. São Paulo: Paz e Terra, 2011.

GEERTZ, Clifford. A Interpretação das Culturas. Rio de Janeiro: LTC, 1989.

HALBWACHS, Maurice. A Memória Coletiva. São Paulo: Centauro, 1993.

IPHAN. Conjunto Histórico e Paisagístico de Oeiras: Dossiê de Tombamento. Teresina: Iphan/MinC, 2009.

MORAIS, Sara Santos; RAMASSOTE, Igo Martins. Trajetória e desafios do Inventário Nacional de Referências Culturais (INRC). Entrevista com Antonio Arantes. Revista CPC, São Paulo, n. 20, p. 221-260, dez. 2015.

NORA, Pierre. Entre Memória e História: a problemática dos lugares. Revista Projeto História, São Paulo, n. 10, p. 07-28, 1993.

UNESCO. Organização das Nações Unidas para a Educação, Ciência e Cultura. Convenção para a Salvaguarda do Património Cultural Imaterial. Paris: UNESCO, 2003.

PINHEIRO, Áurea Paz. As ciladas do inimigo. As tensões entre clericais e anticlericais no Piauí no início do século XX. Teresina: Fundação Cultural Monsenhor Chaves, 2001.

PINHEIRO, Áurea; MOURA Cássia. Celebrações. Teresina: Educar: Artes e Ofícios, 2008.

PINHEIRO, Áurea; MOURA Cássia. Senhores de seu ofício: a arte santeira do

Em Questão, Porto Alegre, v. 26, p. 235-260, Edição Especial Dossiê Patrimônio e Culturas Tradicionais, 2020 | 259 doi: http://dx.doi.org/10.19132/1808-5245260.235-260 
Piauí. Teresina: Educar: Artes e Ofícios, 2009.

PINHEIRO, Áurea da Paz. Museums and cultural heritage: for an education of the senses. Educ. rev. [online], Curitiba, n.58, p. 55-67, 2015.

SANTOS, Boaventura de Sousa. Para além do pensamento abissal: das linhas globais a uma ecologia de saberes. Novos estudos CEBRAP, n. 79, p. 71-94, 2007.

SANTOS, Milton. Metamorfoses do Espaço Habitado: fundamentos teóricos e metodológicos da geografia. Hucitec: São Paulo, 1988.

THIOLLENT, M. Metodologia da pesquisa-ação. São Paulo: Cortez, 1985.

THOMPSON, Paul. A voz do passado. São Paulo: Paz e Terra,1998.

VARINE, Hugues de. As raízes do futuro: o patrimônio a serviço do desenvolvimento local. Porto Alegre: Medianiz, 2013.

\title{
The inventories of the Bom Jesus dos Passos Celebration, Oeiras, Piauí, Brazil
}

\begin{abstract}
The Northeast of Brazil is not massive and unique, Piauí is also a territory crossed by singularities, rich and complex in natural and cultural heritage, which are still to be investigated, recorded, communicated and safeguarded. In this article, we present notes of two inventories of the intangible cultural heritage of the Celebration of Bom Jesus dos Passos, one in 2007 and the other in 2019, in the hinterland of the State. Ten years separate these inventories prepared by an inter and multi-professional team, with the collaboration of the local communities that hold the heritage. We have built diverse looks and perceptions of the world, which have allowed us to collect and record shapes, colours, movements, role-plays, theatrical performances and dialogue mediated between heritage, territories and communities. We were able to narrate memories and stories of the Celebration, which mark the daily life, which deepen the bonds of people's identities with each other. Stories present in the streets, squares, houses, places of memory lived and experienced by devotees in rituals, parties and traditional celebrations of Brazilian culture, northeastern Brazil and Piaui in particular; stories of men, women and children marked by cultural tradition of a present time, in rapid and constant transformation. To carry out participatory inventories is to live with people, to understand that there are no meaningless stories, that it is necessary to find them wherever they are.
\end{abstract}

$\overline{E m}$ Questão, Porto Alegre, v. 26, p. 235-260, Edição Especial Dossiê Patrimônio e Culturas Tradicionais, 2020 | 260 doi: http://dx.doi.org/10.19132/1808-5245260.235-260 
Keywords: Intangible Cultural Heritage. Piauí. Participatory Inventories.

Recebido: $31 / 07 / 2020$

Aceito: 29/09/2020

\section{Declaração de autoria}

Concepção e elaboração do estudo: Áurea da Paz Pinheiro, Rita de Cássia Moura Carvalho, Francisco Stefano Ferreira dos Santos

Coleta de dados: Áurea da Paz Pinheiro, Rita de Cássia Moura Carvalho, Francisco Stefano Ferreira dos Santos

Análise e discussão de dados: Áurea da Paz Pinheiro, Rita de Cássia Moura Carvalho, Francisco Stefano Ferreira dos Santos

Redação e revisão do manuscrito: Áurea da Paz Pinheiro, Rita de Cássia Moura Carvalho, Francisco Stefano Ferreira dos Santos

\section{Como citar}

PINHEIRO, Áurea da Paz; CARVALHO, Rita de Cássia Moura; SANTOS, Francisco Stefano Ferreira dos. Os inventários da Celebração de Bom Jesus dos Passos, Oeiras, Piauí, Brasil. Em Questão, Porto Alegre, v. 26, p. 235-260, Edição Especial Dossiê Patrimônio e Culturas Tradicionais, 2020. Doi: http://dx.doi.org/10.19132/1808-5245260.235-260 